\title{
ABRIR HORIZONTES: UNA PROPUESTA-LECTURA EN LA VIEJA CUESTIÓN DE MYTHOS/LOGOS
}

\author{
ROBERTO QUIROZ PIZARRO \\ Universidad de Chile. Chile
}

Resumen: El pensamiento filosófico cuenta con una larga tradición de siglos, avalada por los escritos, las investigaciones y las escuelas en constante relectura de los grandes clásicos. A tal punto llega la seguridad en la disciplina que se ha sentenciado "la filosofía es patrimonio Occidental". El trabajo es una propuesta, una lectura personal y a distancia de lo que ha parecido tan evidente, que la filosofía comienza en Grecia.

Palabras clave: Filosofía, mito, logos, Occidente.

\section{OPEN HORIZONS: A PERSONAL PROPOSAL ABOUT THE OLD QUESTION OF MYTHOS/LOGOS}

Abstract: Philosophical thought has a long tradition of centuries, supported by writings, investigations and the schools in constant rereading of the great classics. So great is the security in the discipline, that it has been said that "philosophy is a western patrimony". The work is a proposal, a personal reading and at a distance from what has seemed so evident, that philosophy begins in Greece.

Key words: Philosophy, myth, logos, West.

Recibido: 29.12.15 - Aceptado: 27.01.16

\section{Correspondencia: Roberto Quiroz Pizarro. \\ Email: alfanamaste@hotmail.com \\ Lic. Mag. / Filosofía - Universidad de Chile.}

(c) Doctor Universidad de Chile -- (c) Doctor Universitat Jaume I-Valencià 


\section{Esas primeras lecturas}

T a experiencia del lector normal, aficionado a llevar una lectura

Uvariada en humanidades, habrá notado que cuando llega a sus manos un Manual o Historia de la filosofia, inevitablemente le asaltan unas palabras, "mythos", "logos", "el milagro griego", "orientalismo", que pasan a ser acompañantes en las más diversas formas y situaciones. Todo sucede cuando los textos pulsan los acordes del origen o escenario primigenio en donde la filosofía habría tenido lugar, tradicionalmente entre las huellas del mito y del logos, en las riberas orientales del mediterráneo y en los hombros y manos del pueblo griego. Tomando en cuenta al autor, al historiador, al filósofo, a la escuela intelectual o al estudioso de la filosofía como tal, así será también el acento y la topografía con que se dará curso a esa vieja discusión de mythos versus logos. Entonces, como lectores empezamos a sospechar que la historia de la filosofía comienza bajo la sombra de un "talón de Aquiles", de unas incertidumbres que atañen nada menos que a su carta de natalidad y a su naturaleza misma. Las respuestas que se han dado pueden con toda validez no satisfacer al lector, y ahí comienza una odisea a la medida de cada cual. ¿O es que la filosofía gusta de ser polizonte, de viajar a Ítaca encubierta y fuera de borda, y que al igual que Ulises se siente abochornada, incómoda al perder el anonimato, justo en el momento en que la criada le acaricia la pierna y reconoce la cicatriz? ¿O es que ante esta pregunta imaginaria hay que decir que ella también gusta del enigma, y que no está disociada de expresiones como "En el principio existía el..."? Con este indagar queremos por nuestra cuenta ver lo que se nos ha contado o simplemente mirar en el complejo paisaje, e incluso hacer círculos tras círculos. Al menos esa sería la intención de fondo.

En la conformación de esa bipolaridad de mythos/logos, tan fuerte, tan dominante, traducida simplemente a "razón" (racionalidad-calculabilidadargumentación-verdad-conocimiento, más una larga lista) versus "narración, cuento, leyenda, fantasía” (creencia-imaginería-fe-irracionalidad-errorfalsedad-ignorancia y más palabras), se fue haciendo la jugada de pretender medir una instancia por la otra, o de esperar recibir de una lo que la otra poseía. Al mito se le pedía información ajustada a lo que unos entienden por filosófico --a lo que se convirtió en tradición, "filosofía es esto"--, a lo que predominó culturalmente y que parece estar operativo en todas las mentes humanas, una 
forma de pensar y usar el lenguaje que acontece mediante la racionalidad. Este mecanismo conformativo daba la impresión de que a nivel de respuestas el mito era una caricatura, un signo decadente, una elaboración infantil para acercarse a la realidad. En cambio la filosofía y el atribuido triunfo de la razón, despertaron el asombro ante la dimensión y manera de la expresividad usada, pues ya no era el dios relámpago o Zeus mismo, quien servía de imagen para explicar los fenómenos humanos y naturales, sino que cambió la noosfera del pensamiento humano. El nuevo pensamiento pareció un acero indestructible. El razonar se vio como un acto filosófico por excelencia. En cambio, todo ese trasfondo de paganismos, religiones, mitologías, simbologías, magias, oráculos, solo recibió el descrédito y la vaciedad, nada más que considerados cual relatos, cuentos, rituales, imaginaciones, incapaces de dar respuesta en el estilo solemne en que se filosofa con nombre y apellido: a partir de los filósofos griegos del siglo VI a.C.

Durante una larga historicidad se fue gestando pues un menosprecio casi vital por lo mítico-mitológico y una idolátrica confianza enceguecida en la matriz de la razón y lo racional, adjudicándoseles tales propiedades a las ciencias y las filosofías. La cultura en la que estamos lo decreta, y nuestro lenguaje-pensamiento prosiguen esos dictámenes de un logos prodigioso. Hemos ganado la confianza suficiente en que desde la razón, desde la ciencia o la filosofía (ajustada a ese paradigma lógico-conceptual-argumentativo) el hombre puede alcanzar la verdad, debe hacerlo incluso, y que ella puede dar garantías de un conocimiento portentoso y universal, alejándose de las telarañas del mito. Estas breves palabras resumen más o menos lo que creemos que ha sucedido desde "el milagro griego" en adelante.

La nueva facultad desarrollada, el insuperable instrumento de la razón y su efecto mágico en el lenguaje, otorgan el valor de lo incuestionable a lo que sea saber pensar y articular las palabras conforme a la cultura, al barniz de hijos letrados de Occidente que todos poseemos. Desde que razonamos o que sabemos razonar o que vivimos en la racionalidad, o a partir del momento mismo en que nos descubrimos habitantes del logos y facultados por obligación a ser racionales, la posibilidad de actuar guiados por el conocimiento del mundo (científico, histórico, filosófico) se ve como algo evidente, tan evidente que no se cuestiona. De las palabras vamos ahora un poco a los hechos de la vida real y preguntemos ¿qué acontece hoy con la filosofía no académica, con esta amigable lectura que apasiona y enciende debates y que genera noches en vela? 
Vamos a un texto de mucha difusión no académica, pero que cuenta con buen diseño y gráfica, atractivo en su formato de lectura. Al comenzar el libro destinado al gran público --y que por eso mismo debería poner sumo cuidado en la información que va a entregar - se aprecia de entrada esa desconcertante pregunta de qué sea la filosofía:

"La filosofía no es un coto tan sólo reservado a pensadores extraordinarios y excéntricos, tal y como se suele suponer. Todos filosofamos cuando no estamos inmersos en nuestras tareas cotidianas y tenemos la oportunidad de hacernos preguntas sobre la vida y sobre el universo [...]

La filosofía consiste más en el proceso de intentar encontrar respuestas a preguntas fundamentales mediante el razonamiento, sin aceptar las opiniones convencionales o la autoridad tradicional antes de cuestionarlas, que en el hecho propiamente dicho de encontrar esas respuestas. Los primeros filósofos de la historia, en la Grecia y la China antiguas, fueron pensadores a los que no satisfacian las explicaciones establecidas procedentes de la religión y de la costumbre, y que buscaron respuestas con una base racional".

Se diría que se trata de una respuesta positiva, precisa, acotada, posible, que va en una línea tradicional pero que también amplía la presencia misma de la filosofía en la sociedad, dándole el privilegio a la hora de encarar las grandes cuestiones del ser humano. La filosofía está aristotélicamente viva, es parte de la naturaleza humana. Plantea la alianza natural entre razón y preguntas y respuestas, y por tanto, es el camino más seguro y al alcance de todos. Digamos que no siempre hay respuestas así de gratas y hospitalarias entre los filósofos, o incluso, en un mismo filósofo pueden haber varias respuestas parciales o contradicciones, y hasta silencios... Siguiendo esa línea general del texto se puede agregar que a estas alturas también somos una "sociedad del conocimiento", lo cual podría interpretarse de que el mismo conocimiento --logos, racionalidad en bruto- ha adquirido una extensión y volumen tales que está fuera de todo dominio humano. Fuera de control. Como decir que

1 Cosar Editores S.A. 2011: 12. 
desde el propio conocimiento nos damos cuenta de un límite o de un imposible.

Entonces, ¿qué nos puede quedar?

Tal vez el mythos.

Otro autor a su modo vislumbra esa trampa o tarea paradojal que fue ingratamente decretada para la filosofía:

"La misma filosofia, que en otro tiempo había llamado en su ayuda a todas las ciencias para fabricar una imagen coherente del mundo y un cuadro atractivo del bien, encontró su tarea coordinadora demasiado ingente para sus fuerzas, huyó de todos estos frentes de batalla de la verdad y se ocultó en recónditos y estrechos callejones, en tímida búsqueda de un refugio seguro contra los problemas y responsabilidades de la vida"”

Más que verlo como un comentario corrosivo hacia la filosofía en sí, habría que ver ahí el gesto suicida o valeroso de quien reconoce que el conocimiento en Occidente -léase logos - se ha convertido en algo demasiado enorme o endiosado para la mente humana. Y si para esa supuesta demanda o finalidad adjudicada a la filosofía, ¿qué sucede si cambiamos esa abismante demanda por otras aspiraciones o motivaciones a menor escala? A su modo, ¿el mythos era o no era un "factor de comprensibilidad"? O más bien ¿cumplía a veces o siempre una función comprensiva de la realidad humana planteada en paradigmas a fin de resolver asuntos y conflicto del vivir? Incluso, alguien puede ampliar lo que sea la pregunta por el sentido de lo filosófico mismo, y abrir fronteras hacia lo mítico. "Si la filosofía es algo, es, sobre todo, tratar de entender algo de los demás y del mundo y sacar conclusiones", lo que parece también un oportuno llamado a la prudencia y a la anti megalomanía, o ¿es que la filosofía no debe renunciar a la totalidad o al mayor logro impuesto que sería llegar al sentido, al ser, a la divinidad, al misterio, a la realidad misma de todas las cosas? Por otro lado, sí que tenemos una mezcla vital de fuerzas, impulsos, necesidades, deseos, imperativos, libertades, pasiones que nos

2 W. Durant 1978: 14.

3 C. Thibeaut 2003: 9. 
llevan a conocer, lo que parece concordante aristotélicamente con lo que se ha mencionado. Sin embargo, hay oscuros matices que me traicionan, y lo digo así en primera persona, pues me parece que más que tener una idea, un mapa mental o racional de algo o de esas totalidades, a veces creo que más bien busco un contacto directo, una experiencia, una vivencia, y tal vez esta situación personal la traduzco a mi manera en una tensión propia de mi razón y emociónexperiencia-conciencia, lo que me hace pensar en ese binomio o bipolaridad de mythos/logos. Quizá algunas frases de Dilthey puedan tranquilizarme en estas aporías imaginarias o reales. Dice el autor alemán:

"El espíritu filosófico aparece alli donde un pensador, libre de la forma sistemática de la filosofia, somete a examen lo que en el hombre se presenta aislada y oscuramente como instinto, autoridad o creencia [...] Aparece alli donde se someten los valores y los ideales de vida a un nuevo examen. Lo que aparece desordenado o luchando hostilmente dentro de una época o en el corazón de un hombre debe ser reconciliado por el pensamiento, lo oscuro debe ser aclarado, lo inmediato, lo yuxtapuesto, debe ser mediatizado y puesto en conexión"'4.

Sin embargo también valoro esa zozobra filosófica a dónde me conducen unas líneas como las siguientes, en donde se diría que ellas hunden al más temerario de los filósofos (y su consabido logos o esquemas en discursividad raciocinante), porque (me) cuestionan esa habitual zona de la mirada que se tiene de la filosofía:

"Es tradicional la admiración que siempre ha despertado la filosofía y los hombres que ostentan el aún augusto título de "filósofos", entre el común de los mortales. Este sentimiento va mezclado al temor y la confusión y, en tanto que para algunos la filosofia parece sólo accesible a los espíritus selectos, el hombre ingenuo piensa que puede muy bien ser feliz prescindiendo de ella. Otros hombres, sin poder apartarla completamente de sus vidas, conciben el pensamiento humano en general ya

4 W. Dilthey 1944: 200. 
como irremisiblemente envuelto en las densas sombras que proyectan los filósofos a través de las generaciones, ya como tiniebla sin estrella redentora, ya apenas como un aletear de esperanza en este valle de lágrimas [...]

Entre tanto, los filósofos profesionales afirman invariablemente una gran confianza en sus propias opiniones y mucho menos en la filosofía misma. Algunos de ellos son, por cierto, lo bastante francos como para admitir que en realidad ignoran qué es la filosofía. Tal concepto es mucho menos sorprendente que el hecho de que existan hombres dispuestos a expresarlo. Porque, ¿qué puede ser más absurdo que confesar, la final de una vida de labor intelectual, que no se tiene una idea clara acerca de la tarea cumplida?"'.

Y uno impertinentemente preguntaría, ¿no será que tales cosas ocurren debido a que la filosofía oficial, academicista, libresca, se ha convertido en una tradición o canon que se perpetúa a sí mismo, y olvida el mythos o el silencio del logos?

\section{Aristas mítico-conceptuales}

Diferentes trabajos, comentarios, análisis especulativos, modalidades descriptivo-comparativas, multiculturales, etc. han tomado parte en la controversial cuestión de lo que sea la filosofía o de lo que yace en ella como eco fantasmal de unos elementos o de una génesis identificada como confrontacional, yuxtapuesta y hasta excluyente de otros núcleos ideológicos. En tal sentido, lo que ahora exteriorizamos se encamina como un gesto de protesta a modo personal respecto del tratamiento dado a los temas implicados, pero a la vez y no por ello, dejando de lado los aspectos generales, aquello sobre lo que investigadores y filósofos han dado pasos y planteado puntos de vista relevantes e interesantes.

Dentro de un campo vivo como el pensamiento y como los apogeos de la razón filosófica, es que puede establecerse una suerte de observación "en

5 D. Barrow1956: 18. 
vivo" construida en el paso de los siglos. Por lo mismo, se tiene la posibilidad de mirarla en retrospectiva y darse cuenta de sus mutaciones, oscilaciones, líneas de corte y continuidad, extravíos y reencuentros. En esa trayectoria se dan aristas conceptuales que en el tiempo se vuelven recurrentes y que acosan a los que se consideren excursionistas en un terreno tan sorpresivo como la filosofia misma, y a todos por igual valga decirlo, a los curiosos, a los investigadores, a los amigos lectores pero también en cierta medida a los estudiosos de ella y profesionales, si acaso sea legítima la expresión.

Una de esas cuestiones disputadas que se encuentran en tensión versa sobre el camino hacia el origen de la misma disciplina y el estrago dejado en la forma y el espíritu con que se la mira y también cómo la ejecuta cada actor que ha filosofado sabiéndolo o no. Un poco sucede que la naturaleza extraña del fenómeno como tal -de eso llamado filosofía--, empaña la visión de lo que sea ella y de su razón de ser. En cierto sentido, la tiniebla conceptual parece también ser parte de su naturaleza intrínseca, o es que la filosofía como malcriada hija puja por transitar hacia o por tomar accesos en los caminos del arte, de la religión, de la ciencia, y no muy a sabiendas o casi por accidente involuntario. Si por ejemplo fuéramos a hablar de zapatos o de la medicina, entonces, el sentido de las palabras, de los objetos o de la actividad mediadora estaría delante de los ojos con su justa claridad. No habría una controversia tan de fondo en la observación de eso llamado objeto o actividad como los ya aludidos, pero sí lo que acapara nuestra atención fuera un problema filosófico o la presencia de una carta de natalidad para dar cuenta de la filosofía misma, de su gestación, de su contexto o impulso individual, entonces, difícilmente todos coincidirán en lo que se entiende y esencializa por este campo vivo del pensamiento que también está envuelto en el deseo humano por apresar algo con las redes de esta disciplina. Asimismo, casi como en actitud de convención y adopción de paradigmas vencedores, se tiende a topificar y hacer uso de nociones conceptuales sin haberlas examinado a fondo de modo satisfactorio. En tal sentido, la tradición intelectual o la cultura ambiental ad hoc ha consentido en mayor o menor medida en venir a decir que desde la ciencia o la religión llegamos a diferentes puntos o cumbres, y lo mismo valdría para la filosofía. Esta me parece una afirmación más de tipo metodológica y fractálica, similar al hecho humano de tomar algo entre las manos y dividirlo en partes para poder ir penetrándolo en sus capas. No podría precisar en lo personal que la ciencia, la religión o la filosofía son de tal manera que no se encontrarán en una parte del camino o incluso, que en la meta final -isi es que la hay!-- de este extraño 
fenómeno humano que es indagar, cuestionar pero también teorizar e imaginar en los trasfondos de la realidad misma y en sentido plural, las fronteras entre ellas no podrían ser más aparentes que propiamente reales. ¿Cómo saberlo?

Lo que pudo suceder en estas actividades en desarrollo y más aún en los albores de la misma --precisamente, en sus etapas previas y antes de ser vistas como disciplinas, instituciones, organismos socializados, grupos corporeizados--, contiene todo un trasfondo de especulaciones y puntos de vista culturales, implica toda una toma de posturas y asimismo la necesidad de traer consigo aires relativistas de todo fenómeno cuando está naciendo y abriéndose camino en la tradición del conocimiento y del quehacer intelectual. Asuntos como ciencia, filosofía, han sido vistos como fuerzas de choque y de cambio en frente de otras variables como la mitología, la religiosidad, la magia, la astrología o la literatura de un pueblo ejemplar. A tal punto lo interpretamos así, de tal modo, que frecuentemente suele señalarse que la civilización occidental tiene como lugar de alumbramiento las márgenes mediterráneas de lo que conocemos como Grecia.

En la búsqueda de lo que sería el estatus propio de estas actividades, la del poeta, la del mago, la del profeta, la del científico, la del filósofo, se atraviesan unos tópicos y consignas que siguen dando mucho que hablar. Asimismo, para explicar o despejar el surgimiento de la ciencia o la filosofía al estilo occidental en que más lo conocemos, se recurre al consabido juego dialéctico de logos versus mythos --de discurso racional versus discurso mítico, de la diosa razón versus mundo de la fe, de la razón versus lo empírico, o de la fe versus la experiencia misma--, de modo tal a fin de marcar o establecer una diferencia y distanciamiento crítico o de naturalezas entre estos dos ámbitos humanos.

En Byzantion Nea Hellás $\mathrm{N}^{\circ}$ 21, "La originalidad del discurso filosófico" y en el vol. $n^{\circ} 30$ de la misma colección, "Sobre verdad y falsedad en el mito griego. Pistas desde la filosofía para concebir un modo de verdad en el mito" 6 , respectivamente, se encuentran trabajos que intentan dar respuesta

6 Estos trabajos se unen a muchos otros autores en los que cada uno adhiere a un tópico, definición de campo o paradigma, para darle las dimensiones que ve como legítimas a la filosofía y a las otras actividades que generan o fabrican un contenido intelectual, una creencia o un patrón mental. Por razones de espacio y no de un retroceso en la marcha, no podemos entrar en los detalles característicos de todo lo 
desde diferentes puntos de vista a ese espectro señalado y también hacer más comprensible lo que sea que quiso ser la filosofía en su venida al mundo. En razón de ese aún no claro del todo sentido de lo autóctono y del rostro individual que la filosofía ofrece para mirar la realidad o realidades, es que aquí intentamos abrir un camino de paisajes más que de puntos de llegada definidos, estáticos y rectilíneos. En esos artículos (Jeria, Madrid) queda constancia de la variedad de opiniones y perspectivas que pueden alcanzar unas nociones como ciencia, filosofía, mito, religión, verdad, falsedad, realidad, apariencia y otros, que mantienen en disputa a los propios lectores y estudiosos de la filosofía en general. Cuestiones que así se problematizan y tornan disputadas nunca deberían morir para el aficionado ni para el ilustrado académico, e incluso, en la medida misma del paso del tiempo el volver sobre ellas debería ser una cuestión necesaria con la esperanza de lograr quizá otro acercamiento cara a cara con la filosofia misma.

Nos movemos históricamente con la vaga sensación de que la filosofía acontece bajo un signo de relativa propiedad y corporeidad, y que ni siquiera el acuñamiento del tiempo puede borrar ése, su enigma generativo, el de un "de dónde proviene" y "qué entraña en sí misma", como si fuera un oráculo a descifrar. La filosofía misma como disciplina y acto intelectual de contrapeso en la cultura occidental carga de por sí con ese estigma de origen y sentido. Asumimos en esa disparidad de opiniones y juicios que de por sí señalan los entendidos, que se trata de una realidad paradojal -a lo menos problemática--, y de una de esas empresas al límite y que por lo tanto, son de las que poseen una tensión tópica y una beligerancia ad hoc, comúnmente expresada en la vieja fórmula del mythos al logos o del mito versus logos, o en la fórmula proverbial de un "milagro griego". Por tanto, da la impresión que en esta disciplina del espíritu se ha observado una tensión dramática así de manifiesta y polarizante, y que por tanto, el asunto como tal adquiere una dimensión de raigambre desconocida, y que finalmente, no pueden caber certezas científicas evidentes para inclinar la respuesta de un origen absoluto en el filosofar o de sus causas directas. A menudo se insiste en esa especie de fractura entre lo mitológicoreligioso-mágico y lo no-mitológico-científico-filosófico, en una suerte de

que se ha planteado, y más bien intentamos buscar un camino en que no es nuestra ley la de seguir, validar, asimilar, retomar, criticar, destruir o superar lo planteado por todos. Se mencionan trabajos y autores que han intentado situar un fenómeno como la filosofía. Los trabajos mencionados corresponden respectivamente a Patricio Jeria y Raúl Madrid Meneses. 
tensión intrínseca entre los elementos, como si hubiera habido una cosmogénesis conceptual. Si de verdad viéramos, asimiláramos que es muy complejo filtrar la llegada y gestación de la filosofía más allá de ese km. cero llamado Grecia, entonces, podríamos decir que el fenómeno adquiere en tierras helenas una dimensión mayúscula, que toma el vigor de un gigante y que adquiere alas de Pegaso para no sentirse limitada a una sola tierra. En tal sentido, la evidencia misma de su alta complejidad me parecerían razones suficientes para decretar que el asunto no está resuelto y que no bastaría insinuar que en Oriente no se filosofa - de que no hay una tal filosofia--, aseveraciones que sin embargo, han circulado libremente en los manuales y obras de los multifacéticos filósofos. Lo apuntamos como otro componente más de la polémica y no para tomar partido ni dirimir como Zeus, pues lo que mejor le queda al filósofo como vestimenta propia es la de la indagación, el estar a punto de zarpar en el viejo navío de la investigación o el de ponerse su hábito de "ir de camino" como lo señala Jaspers $^{7}$, con rumbo desconocido o de muchos nombres a la vez.

A unos parecerá en efecto, que la nota dominante es que la figura del filósofo tuvo que abrirse paso a golpe de puños, tal como lo celebra Nietzsche ${ }^{8}$, y concluir que "únicamente en Grecia el filósofo no es algo accidental". Sin embargo, en la misma época, Burckhardt -personaje conocido y respetado por Nietzsche-- fue tajante en señalar que el pensamiento mítico actuó más bien como una rémora, un resabio atávico y no fue más que una cizaña en el camino. A su juicio planteó que "la filosofía comienza en Grecia alrededor del siglo VII a. C., cuando el logos logra liberarse del mythos", o bien que "la filosofía estaba desde el principio violentamente impedida precisamente por el mito". En el mismo abordaje teórico de la cuestión se encuentra otro investigador como Burnet, para quien no hay dudas en el origen occidental de la filosofía o ciencia, y más aún con respecto de la estructura mítico-religiosa, señalándolo claramente: "hemos visto que en Jonia se produjo un completo rompimiento con la primitiva religión egea y que el politeísmo olímpico nunca llegó a sostenerse firmemente en la mente de los jonios. Por tanto, es completamente equivocado creer que la ciencia jonia tuvo su origen en ideas mitológicas de cualquier especie" ${ }^{10}$, lo que una vez más difunde esa aberración ante lo oriental, ante la

7 K. Jaspers 1970: 23.

8 F. Nietzsche 2003: 15.

9 J. Burckhardt 1964: 402.

10 J. Burnet 1944:15. 
posibilidad de que la filosofía tenga nexos lejanos o que el horizonte discursivo de mythos-logos pueda conectarse de algún modo.

Más cercano a nosotros, en plena mitad del siglo XX, otro estudioso alemán sostenía lo de la gran hazaña del "milagro griego" y de la escasa deuda con el pensamiento oriental en general, lo cual es otra forma de plantear la vieja controversia entre mythos y logos o de instalar hegemónicamente el discurso del eurocentrismo sin filtros. Así lo escribe Capelle:

\section{"La misma palabra filosofía muestra que tenemos} que agradecer al genio griego la instauración de la «reina de las ciencias». Porque lo mismo que la matemática, la medicina cientifica, la geografia, es también la filosofia un fruto absolutamente original del espiritu griego o, más exactamente, del jónico. Aunque a mediados del siglo pasado se mantuvo con asombrosa obstinación, que se mostró inasequible a toda crítica científica, la opinión de que la filosofía griega había recibido influjos decisivos de culturas orientales, ya sean de origen egipcio, fenicio, babilónico, persa o incluso indio, ha sido, sin embargo, y ante todo a través de un profundo examen de la cuestión, llevado a cabo por Zeller, como se ha llegado a poner fin, esperemos que definitivamente, a tales fantasias faltas de solidez cientifica" ${ }^{11}$.

Entonces, en Capelle, lo medular de esta naciente actividad entre los griegos no sólo sería el uso del logos o la operatividad de la razón o la llegada de la racionalidad al pensamiento humano, sino la paternidad incuestionable que moraría sobre la filosofía por parte del pueblo griego. Por otro lado, donde quiera que nos ubiquemos, situemos, estamos culturalmente sitiados, remitidos a una tradición que nos mantiene en un juego tensional de individuo y sociedad, de individuo y comunidad, de sujeto y masa, de sujeto y colectividades, de sujeto y grupos organizados, etc., en donde el conocimiento va a tensionarse o se va a plasmar en términos de causalidad, oposición, gradación, matización, influjo entre individuo y escuelas, entre individuo e institucionalidad, entre individuo y comunidad de pares, lo cual permite a la postre la generación de un corpus

11 W. Capelle 1992: 7. 
y de una tradición. Sin embargo, los primeros filósofos, los presocráticos o la figura de Sócrates, filosofan más por cuenta propia que siguiendo una tradición, libremente según lo enfoquemos, y su gesto individual está pensado como perteneciente a toda la humanidad que pueda aventurarse en el pensamiento. También promueven un pensamiento que vemos individualizado, planteando lo que no está necesariamente validado por una tradición, y quizá hasta con cierto aire de rebeldías. Asimismo, se podría teorizar que es un momento en el que la atracción y la fuerza llamativa hacia la filosofía no depende a un cien por cien de la racionalidad dura o del logos al desnudo, porque si bien hay un movimiento de pensamiento más elaborado y despierto racionalmente, no se tiene por normatividad aún ese menosprecio por el mito y su legado natural o cultural, y hasta Platón mismo hizo uso personal del mito para filosofar y darle luz a sus planteamientos de más alto vuelo y complejidad. Por eso también surgen voces disidentes que no toman esa dirección de ruptura y menosprecio de lo que no sea un elemento puramente racional o mitológico o antirracional. Autores como Roger-Pol, Jean Philippe de Tonac, matizan a su modo esa tensión oficialista entre mythos y logos, mythos y pathos, logos y pathos. ¿Se elije una filosofía nada más que por el corte intelectual de la misma? Al respecto, los autores apuntan:

"Hasta hace pocos años, se consideraba a los filósofos de la Antigüedad como teóricos y nada más. Se veía en ellos a creadores de sistemas, a fabricantes de conceptos $[\ldots]$

En efecto, hoy se redescubre que la filosofía constituia un modo de vida particular. Implicaba ciertas formas de actuar, impregnaba los gestos cotidianos.

Afectaba el estilo de vida: formas de alimentarse, actitud política, relación con los demás y con uno mismo.

Por lo tanto, una parte importante de la filosofía no residía en los libros [...]

Hecho muy simple: lo que más solía atraer a tal o cual escuela filosófica en la antigüedad no eran las lecturas o las preferencias teóricas, sino el encuentro con un maestro. El efecto que provocaba, la seducción o la fascinación $" 12$.

12 D. Roger-Pol \& Jean Philippe De Tonac 2003: 7. 
Asimismo, en toda esa estructuración racionalista-lógico argumentativa crítica- tan asimilada al mundo intelectual mental, al logos en general, habría quienes depositarían en esta actividad que llamamos campo conceptual e ideológico, la necesidad de incorporar otra dimensión antropológica, dando a entender que el propio logos no bastaría por sí mismo o que debe ser asimilado de un modo holístico, sin exclusiones del fenómeno humano. En un viejo texto de Morente se alude a la dificultad inminente en tratar de definir lo que sea la filosofía, haciéndola consistir en más que un estricto ejercicio teórico y especulativo. Como actividad es un hacer humano que adquiere realidad en el ejercicio de la profesión de ser hombre, y así lo señala el autor español, "sólo sabrán ustedes qué es filosofía cuando sean realmente filósofos; por consiguiente, no puedo decirles lo que es filosofía. [...] Esto quiere decir que la filosofía, más que ninguna otra disciplina, necesita ser vivida. Necesitamos tener de ella una "vivencia"”, ${ }_{13}$. En pocas palabras, lo que se apunta es que no debe haber un abismo insalvable entre el logos y la experiencia misma, entre teoría y vivencialidad de las realidades por las que atraviesa el propio hombre.

\section{¿Otra posibilidad a la de alejamiento/acercamiento entre mito y logos?}

La palabra como punta de lanza intelectual y como armadura para enfrentarse a los misterios humanos y de la vida nos lleva a pensar en Grecia. Por tanto, Grecia como un escenario de conflictos y respuestas en el tiempo. Nos agrada pensar que nuestra referencia a la palabra transita mediante el logos primigenio y de la mano de antiguos filósofos que abrieron un camino: a la verdad, a la razón, a un nuevo mito sobre la verdad/sobre la razón o incluso, de un más allá de la razón. No nos queda claro todo lo que haya sido la dialéctica interna de mythos y logos. Sabemos sí que la tradición ha visto a la filosofía como un resultado valioso de todo ello.

En lo cultural nos sentimos hijos de una Elena sitiada en el espacio mítico, a quien rescatamos cada vez que comenzamos a filosofar -esto es, a pensar en la vida y en el mundo. Por tanto, las ruinas de Troya y las manifestaciones de la cultura griega nos llevan a sospechar que allí se enfrentaron las fuerzas ancestrales del mito con las del logos, y que nuestra occidentalidad -un factor de identidad - detenta viejas cicatrices (señaladas aristotélicamente) como 
aquello que "todos los hombres por naturaleza desean saber"'14. Sin embargo, ese logos parturiento y quizá también anónimo de los primeros filósofos no tuvo un aula, tampoco había un camino trazado y por tanto, no se sabía bien si lo suyo era lo mismo de lo que hacían poetas, sabios o visionarios que pretendía tomar contacto con la realidad.

Dentro de una postura más romántica que racionalista están los que consideran que la filosofía como manifestación del pensamiento humano no ha sido nunca un hecho tan evidente por sí mismo. Por el contrario, la filosofía pasa a ser una disciplina que exige la explicación de su nacimiento y de su desarrollo a través del tiempo. La filosofía "occidentalizada" -que vendría a ser observada en los límites de una retrospección imaginaria-- se presenta en la historia de la cultura bajo contrapuntos y saltos de numeración, tal como en una serie de escenas iniciales faltantes -pero más bien decimos faltantes a modo de comodín, porque ahí está el problema de sus inicios. Por ahí, precisamente, apuntan las metáforas de cuando se nos habla con cierto dejo de enigma de que existió algo así como "el paso del mito al logos" o bien de que hubo una revolución nominada "milagro griego". Estas metáforas de prestigio en la tradición occidental patentan la llegada de la filosofía como si hubiera un punto cero en el mismo pensamiento.

Con esas dos argumentaciones ya puestas a la altura de dogma por la tradición, da la sensación de que la única opción es el atenacentrismo cultural: Grecia como alfa y omega de sí misma. Pero ¿es la única opción?

No es lo mismo tener más opciones o matices y que se vean las cosas como fenómenos dinámicos y de fronteras abiertas a sólo manejar una explicación de todo: es lo que ha sucedido con la afirmación de que por ejemplo, el milagro griego da cuenta de un proceso y por tanto, sería autosuficiente de todo un desarrollo multicultural; o que la filosofía griega es criatura de un parto endógeno, radical y abrupto entre mitos y logos, y en efecto, la especulación mítica y la especulación del logos han de ser tenidas como enemigas para todos los días y noches del ser humano. Juicios de tal naturaleza parecen ir un poco en la dirección de la teoría del choque de civilizaciones, y estar ad portas del otro singular planteamiento del fin de la historia.

14 Aristóteles 1994: 69. 
A lo que se enfrentan los que comienzan a recorrer estos caminos con menos tablas de prejuicios y menos occidentalismo en las venas es a imaginarse otros matices, perspectivas y cruces inesperados. Por ejemplo, en vez de ver allí un solo epicentro de la cultura o del pensamiento racional o de la filosofía occidental, tratar de pensarlo así: Atenas, punto de partida para el logos; Atenas también punto de llegada; Atenas como zona de transición; es decir, Atenas en una encrucijada de inicio, consumación y proyecciones.

Afortunadamente las opiniones están divididas. En un caso extremo están los llamados orientalistas cuyo punto de vista fue "todo proviene de Oriente", y donde la filosofía occidental es tenida como patrimonio de esa latitud; por otro lado, están los clasicistas que enfatizan sus diversas posiciones creyendo que Grecia iluminó con luz propia la faz pensante de los hombres.

Como occidentales estamos sesgados culturalmente para emitir un juicio así de categórico y más aún, parecería un acto de hybris homérica, adoptar una toma de posición en que se presume que Oriente no filosofa sino que duerme en una mitología interna y que cuando quiere pensar asoma sus manos como en la gesticulación del pordiosero de la escudilla a fin de que le den lo que no posee: logos --idadme logos occidental! Tampoco se trata de buscar una posición acomodaticia entre Orientalismo y anti-orientalismo para no cuestionar más el asunto o para quedarnos así de tranquilos, sino más bien es un intento por adoptar la actitud de estar abiertos a una conciliación o reubicación semántica que aún está pendiente. En ese compás de espera, preferimos pensar que la filosofía es patrimonio humano --Oriente y Occidente--, sin exclusiones, reconociendo eso sí que en Occidente y a través de los griegos hemos podido apreciar más de cerca el logos, como si los griegos fueran justo un eclipse --paradojalmente luminoso-- que acontece en el soberano reinado del mito, y que tal fenómeno nos permitió saber a dónde mirar por unos instantes.

Por ello miramos al mundo griego y vemos que la filosofía no pudo llegar al mundo como un repentino estallido del pensamiento humano, como una suerte de innovación revolucionaria, como un imprevisto y radical cambio, sino que más bien habría que mirarla como manifestación o resultado inesperado de una gradual incubación que comenzó desde antiguo. Es como si la Grecia mítica hubiera sido un período de gestación para el logos filosófico y no lo que se imagina que fue un abrupto paso del mito al logos o un radical corte inicial bajo el milagro griego. En perspectiva contemporánea hay quienes 
ya vislumbran ese enfoque menos oposicional y dicotómico entre las fuerzas emergentes de cada cultura. Se tiene indicios de que a comienzos del siglo VI en adelante hay una gestación y difusión de ideas filosóficas y de sistemas de pensamiento originalmente articulados y fuera del marco convencional, los que avanzan por lugares dispersos y lejanos del globo. "Alrededor del Mediterráneo $y$ de Oriente Próximo, en la India y en China, aparecieron los filósofos, grandes filósofos cuyas ideas establecerían los términos de la filosofía en sus diversas tradiciones durante los milenios siguientes [...]

De hecho, resulta más preciso considerar el gran "milagro" de la Grecia antigua no como un inicio extraordinario sino como la culminación, el climax, de una historia cuyos comienzos hemos olvidado" ${ }^{15}$.

¿Puede haber una perspectiva en donde sea posible jugar con esa bipolaridad mythos/logos y donde ambos elementos buscan su propio sitio, su espacio, su horizonte de sentido? Parece una tarea en dos momentos: un ir hacia una interpretación contextual y cultural, en donde uno puede vislumbrar las cosas o acciones pre-sociabilizadas, míticamente, antes de que hayan caído en el juego de fuerzas y ser trofeo de una facción. Y por otro lado, es mirar intelectualmente el asunto, quizá algo así como contaminar con logos lo que se trata de estructurar, aquí mythos y por acá logos.

Si ficcionalmente nos preguntáramos cómo queremos que sea la ciencia o la filosofía dentro de una sociedad ideal, entonces, en ese plano una pregunta así tendría sentido, precisando que se trata de una cuestión de orientación o ejercicio intelectualista. Pero qué ocurre si hablamos del mythos, ¿quién pudiera aventurar una respuesta para algo de esta naturaleza? ¿Podría una voz decirnos si acaso el mito bíblico del árbol del bien y del mal, de la ciencia y del pecado, está bien o mal narrado? Claro, se han desarrollado las herramientas hermenéuticas, exegéticas, semánticas, sociológicas, teológicas, discursivas, que parten del hecho dado, "lo narrado", y desde ahí escalan hacia un adoctrinamiento o corpus o depuración del sentido como tal, pero queda fuera de miras el planteamiento anterior. A diferencia de ello ha habido intentos, teorías, estudios, en donde se ha tratado de observar la disciplina y el accionar de los científicos en estado puro, un tratar de mirar sin prejuicios ni apriorismos ideológicos el quehacer de la ciencia. Es una teorización extrema

15 Solomon, R \& Higgins, K, 1999: 16,17. 
tal como las condiciones que rodean al experimento de un laboratorio. Ahora por razones indagatorias imaginemos temporalmente una identidad entre ambas, entre ciencia y filosofía, mirándolas cual unidad. En ese mismo sentido, sabemos que a mitad del siglo pasado la escuela sociológica de Merton ${ }^{16}$ tuvo ciertas inquietudes, como imaginarse lo que sería ver lo que hace la ciencia, ver la actividad misma de los científicos. Obviamente que aquí tomamos ese experimento como un espejo en donde ver lo que sería también un rastreo en el orden de la filosofía, a sabiendas por cierto, que en el mundo griego y entre los antiguos y hasta en autores modernos, no quedan tan claras esas diferencias de frontera entre ciencia y filosofía.

De conformidad a Merton y en ese contexto institucional, socializado, cultural, proyectado idealmente -base de la indagación y teorización sociológica--, se señala que el primer pilar de una ciencia (filosofía, en nuestro ejercicio imaginario) sujeta a la auto-observación y valoración de sí misma, sería el de que ella debe ser autónoma, independiente ante lo fáctico, "libre de toda influencia externa a su propia dinámica". Da la impresión que los mitos judaicos y griegos tuvieron una fuerza tal que impregnaron la cultura y fueron utilizados para ejercer influencia, o sea, fueron vistos en un contexto de más acá, potencialidad en la acción directa de los hombres, es decir, que se los vio como ya actividades comprometidas, intervenidas e intervinientes en la sociedad que los acoge. Haciendo el paralelo, basta pensar en la tragedia griega, en su espectáculo, su fuerza convocadora y en el hecho de ser vista como el alma de la sociedad misma. De algún modo, la ciencia y la filosofía pretenden esa independencia que al mundo mitológico parece no entorpecer.

Un segundo eje de esta actitud o actividad ideal de la ciencia (filosofía) es el fenómeno de la acumulación, la posibilidad de recibir correcciones y apoyos. La frase que mejor grafica este segundo elemento es de que los científicos "se suben a hombros de gigantes" para contemplar más lejanamente, para avanzar en cierto sentido y evitar errores si se quiere. Entonces, la ciencia y la filosofía parecen tener fronteras permeables, abiertas, movedizas, expansivas y que buscan una visión conforme a ello. El mito lo vemos como un paradigma, una llave parametral que tiene atempolaridad y universalidad pero que no parece estar en un proceso de movimiento expansivo finalista, de crecimiento o de autocorrección interna, si no más bien como si estuviera por encima no de la

16 R. Merton 1992: 636 y ss. 
verdad como tal sino de lo que sería la fabricación humana de verdades, el constructivismo social que toma las cosas como provisorias. Verdad y falsedad, parecen no dañar al sentido de lo mítico, a su ejemplaridad y al saber dar respuestas a las cuestiones humanas.

Por último, según el enfoque sociológico auxiliar del que nos valemos, el otro factor de la actividad pura y sin arbitrariedad humana aparente de la ciencia (filosofía) viene a ser la posibilidad de evitar errores, el tener como motivación minimizar los fraudes y engaños. Y ¿cómo promover la honestidad de lo que se hace? Respuesta: a través de una comunidad (científica, filosófica) que lucha contra los conflictos y bajos intereses particulares. Se daría una especie de orgánica, organización normativa, regulación propia que iría de acuerdo a lo que se llama el ethos mismo de lo que se hace, en este caso, algo propio de la ciencia o la filosofía que enmarca y distingue a una comunidad como tal. Aquí emerge una especie de fe o creencia en que la aplicación correcta y sana, adecuada y racional del pensamiento, es la mejor herramienta para que la ciencia y la filosofía avancen sin posibilidad de traspiés. Es como si el científico no pudiera hacer mal su trabajo, o estuviera imposibilitado de añadir sesgos y subjetividad a sus observaciones y pensamientos de cuando trabaja con la realidad del mundo o del sentido de las cosas.

Dentro de la propia mitología y filosofía hay autores que movidos por la complejidad del tema y ampliando perspectivas, buscan, advierten, sociabilizan o rearticulan las conexiones culturales o simbólicas. En esas posiciones de contextualización sociológica del problema, H. D. F. Kitto, afirma que sin tener una clara concepción de lo que fue y significó la polis para los griegos, "es completamente imposible comprender adecuadamente la historia, el pensamiento y las realizaciones de los helenos", opinión que saca de su lugar común a la vieja discusión de mythos/logos. Así se van sumando nuevos filtros hermenéuticos y se complejiza lo que estaba asumido generalmente, o bien se relativizan los conceptos ya un poco fosilizados. Vernant, por ejemplo, defiende la idea de que ha surgido "una razón" socializada, politizada, democratizada, pero no la razón sin más; puntualiza la importancia de la polis como elemento central en el desarrollo de estos procesos, pronunciándose por rescatar lo que considera la aparición gradual de una nueva actitud intelectual presionada desde dentro por los griegos. Por tanto, siguiendo esta visión resulta artificioso hacer depender el destino del pensamiento griego del enfrentamiento frontal de dos términos, como mito y logos sin más. 
A la luz de todo lo señalado, más que conclusiones surgen inevitables preguntas que se esbozan en ángulos escalonados. ¿De qué comienzos, entonces, partió la filosofía en Grecia?

¿Quién pudo tener más peso filosófico a la hora de asignarle un primer lugar en la génesis, Tales de Mileto --candidato aristotélico--, o el mismo Hesíodo ${ }^{17}$ ? Además, por cierto, con su interesante cuestión de la llamada "paradoja hesiódica"18 que los autores han hecho notar. griego?

¿Cuál es el origen del espíritu filosófico en la tradición cultural de lo

¿Es el mito y la religión desde donde emerge gradualmente el logos iluminado, la plasticidad del espíritu griego?

¿Si la filosofía es el resultado de todo un desarrollo precedente, entonces su marco mayéutico viene dado o es una construcción sui generis?

¿Es la filosofía como se dice, fruto de una "potenciación de la polis" o de un proceso de autonomía del logos, de la palabra misma?

17 En general a esto responde la tendencia moderna de incluir en sus páginas las ideas prefilosóficas o, mejor aún, protofilosóficas, contenidas en la larga tradición referida a cantores míticos, a los proverbios gnómicos, a los enunciados cosmogónicos o aseveraciones crítico-escépticas. Por otro lado, diversos autores manifiestan una opinión favorable por el poeta beocio --o por los elementos literario- culturales del ambiente en que aflora--, considerando que en sus textos se da una intencionalidad conexa al espíritu filosófico o bien que es una suerte de herencia que pasa a los que más tarde son llamados filósofos, o incluso, señalar que el legado hesíodico pertenece a la "filosofía no escrita", según Cornford. Se valora el esfuerzo intelectual y así lo piensan Kirk, Raven, A. Martín Sánchez, J. Griffin, O. Gigon, F. Ricken, Jaeger, T. Szlezak, así como otros que son más cautos o contrarios, Lesky, Capelle, E. Severino, y otros.

18 La "paradoja de Hesíodo" señala que los materiales en uso y elementos mítico ideológico y conceptuales que trabaja el poeta Boecio resultan más arcaicos que los de Homero, pero a su vez la manera, el tratamiento, la forma de procesar esos contenidos y narraciones sitúan a Hesíodo más cerca de lo que vendrá a ser el estilo y corriente intelectual de los presocráticos. Por eso algunos plantean una filiación, un tronco común embrionario, un mínimo legado para los nuevos caminantes en la filosofía. 
¿Es la muerte del mito lo que explicaría el naciente interés teórico de los antiguos griegos acerca del mundo?

¿Fueron los griegos los primeros en encontrar un camino para el espíritu racionalista, precientífico, experimental, filosófico?

¿Hay una figura o atmósfera logocéntrica actual y contingente que nos impida mirar en paralelo -y no bajo contradicción--, una sinergía entre mitos y $\log o s ?$

En la filosofía de la sospecha o heideggerianamente hablando, al menos sería un buen inicio tener claridades en las preguntas ocultas y manifiestas, puesto que vienen a ser la navegación misma de nuestro pensamiento.

De un cierto lado, a unos parece verosímil afirmar que los griegos no aspiraron simple y únicamente a objetivos práctico-utilitarios, a saberes concretos y funcionales, y que no fue prioridad propia acumular un conocimiento técnico y pragmático. Por tanto, el desarrollo del logos se entrelazó más bien con el desarrollo de un vigor especulativo global y en todo sentido: mítico, literario, filosófico, precientífico, tal como el que se plasmó en una tendencia de contar narraciones que fueran lo más organizada y ampliamente posible: Homero y Hesíodo son ejemplos de una precisión y esquematismo especulativo en tal sentido.

Asimismo, por otro lado, hay indicios que en el temprano pensamiento filosófico o prefilosófico hubo una presencia de elementos míticos, irracionales, imaginarios propios o en préstamo ${ }^{19}$. En tal sentido, es un hecho directo que los primeros pensadores griegos estuvieron más cerca que otros del pensamiento mítico, mágico y religioso, y puesto que ellos eran los pioneros, los precursores, era natural, lógico y forzosamente necesario, que los primeros ensayos filosóficos o teorizaciones o miradas críticas que emprendieron, pasaran más inmediatamente cerca por entre las sombras del mito y del acervo cultural de los relatos tradicionales - cosmogonías, teogonías, epopeyas míticas. Entonces, a causa de esa misma proximidad se tuvo que dar un efecto de contaminación para bien y para mal.

$19 \mathrm{Al}$ respecto, cf. lo que se documenta en los artículos mencionados de Patricio Jeria y Raúl Madrid. 
Cuando en efecto, decimos que el paso del mito al logos o de la religión a la filosofía, o de los discursos a los credos similares, constituye el acta de nacimiento de la filosofía griega-occidental, entendemos normalmente un paso gradual, no una ruptura o un predominio logocéntrico que tenga que ser excluyente y totalizante. Es una perspectiva riesgosa, reduccionista, eurocentrista, imaginarnos que la filosofía emerge repentinamente como un cosmos iluminado gracias al logos helénico mediante el sombrío mundo del mito y las religiones. Es por lo demás lo que algunos autores han visto con otros ojos, y donde ahora buscan matices, trasvasijes culturales o procesos y paralelismos transversales. Hay un nuevo pensar, en donde se mantiene como tesis la idea de que no es posible ningún paso del mito puro al logos puro. Desde Hesíodo hasta Platón, el mito continúa funcionando en medio del pensamiento racional. Incluso, hay autores que incluso protestan ante esos cortes, rupturas, fragmentaciones, minimizaciones al momento de clasificar el talante intelectual de los pensadores antiguos. Así F. R. Adrados establece un juicio rotundo que rechaza como injustificada la pretensión de generar una división tan tajante entre los autores griegos vistos como poetas, sabios y filósofos.

"No caigamos, pues, en la pedantería de decir que el pensamiento racional sobre el hombre nace en Grecia con Sócrates y Platón. Ni en estos autores es todo racional, a pesar de lo que ellos mismos crean a veces, ni faltan elementos racionales en sus predecesores los poetas y sofistas ${ }^{\prime 20}$.

En tal sentido, seduce la nueva visión en donde la característica constante de la marcha filosófica se muestra como un proceso continuamente abierto de transformaciones de todo tipo de fuerzas - del mito, del logos--, de elementos míticos-religiosos, sociohistóricos, en categorías, conceptos y esquemas

20 Rodríguez, A. F. (1993): 21. Bernabé, A. es otro de esos autores que han abierto los horizontes hermenéuticos y disciplinarios con sus trabajos, críticas, traducciones y exposiciones. Al respecto, el autor es de la idea de que al decir que hubo un juego dialéctico y una reciprocidad mítico-religiosa-filosófica que puso en contacto a dos tipos de especulación, no se está señalando que el primer y único enfoque de la cuestión mythos/logos tenga que ser la perspectiva de una confrontación y una erradicación de un tipo de pensamiento por el otro. Su parecer apunta más bien a una compatibilidad y concordancia pero también a zonas de diferencias y de propiedad en el sentido global de cada cosmovisión. 
racionales de interpretación del mundo, y quién sabe si hasta de un espacio de refundiciones. Entonces, lo que hemos tratado de sugerir en esta observación de paisajes también es parte de un ejercicio en el pensar y en buscar opciones como fue señalado al comienzo: no solo mythos, no sólo logos, sino la interacción, la diferencia de potenciales y naturalezas como estados de una misma necesidad de respuestas y preguntas. Es decir, volvemos a esa Atenas como un punto de llegada, a Grecia como una consumación de procesos y a Grecia como una zona de laboratorio entre mitos y $\log _{0}{ }^{21}$, sin descartar a ninguno.

21 Dejamos a la vista para el lector que por razones de espacio se ha tenido que dividir el trabajo en dos exposiciones. 


\section{REFERENCIAS BIBLIOGRÁFICAS}

ARISTÓTELES. (1994). Metafísica. Madrid: Gredos.

BARROW, D. (1956). El hombre contra el mito. Buenos Aires: Leviatán.

BERNABÉ, A. (2008). Fragmentos presocráticos. De Tales a Demócrito. Madrid: Alianza.

BURCKHARDT, J. (1964). Historia de la cultura griega. vol. III. Barcelona: Iberia.

BURNET, J. (1944). La aurora del pensamiento griego. México: Argos.

CAPELLE, W. (1992). Historia de la filosofía griega. Madrid: Gredos.

CORNFORD, F. M. (1987). Principium sapientiae. Los orígenes del pensamiento filosófico griego. Madrid: La balsa de la Medusa.

Cosar Editores S.A. (2011). El libro de la filosofía. Santiago: DK.

DILTHEY, W. (1944). La esencia de la filosofía. Argentina: Losada.

DURANT, W. (1978). Historia de la filosofía. México: Diana.

ESCOHOTADO, A. (1975). De Physis a Polis. Barcelona: Anagrama.

GIGON. O. (1980). Orígenes de la filosofía griega, de Hesíodo a Parménides. Madrid: Gredos.

JASPERS, K. (1970). La filosofía desde el punto de vista de la existencia. México: FCE.

JAEGER, W. (1992). La teología de los primeros filósofos griegos. México: FCE.

JERIA, P. (2002). "La originalidad del discurso filosófico", Byzantion Nea Hellás vol. 21. Santiago: Centro de Estudios Griegos Bizantinos y Neohelénicos.

KIRK G. S. (1992). La naturaleza de los mitos griegos. Barcelona: Labor.

KIRK, G.S. \& RAVEN, J. \& SCHOFIELD, M. (1987). Los filósofos presocráticos. $2^{\mathrm{a}}$ ed. Madrid: Gredos.

LESKY, A. (1976). Historia de la literatura griega. Madrid: Gredos.

MADRID, R. (2011). "Sobre verdad y falsedad en el mito griego. Pistas desde la filosofía para concebir un modo de verdad en el mito", Byzantion Nea Hellás vol. 30. Santiago: Centro de Estudios Griegos Bizantinos y Neohelénicos.

Merton, R. (1992). Teoría y estructura social. México: FCE.

Morente, M. \& Zaragüeta, J. (1943). Introducción a la filosofia. Madrid:

Espasa-Calpe.

NIETZSCHE, F. (2003). La filosofía en la época trágica de los griegos. Madrid: Valdemar.

RODRÍGUEZ, A. F. (1993). La democracia ateniense. Madrid: Alianza. 
ROGER-POL, D. \& DE TONAC, J. P. (2003).Tan locos como sabios. Vivir como filósofos. México: FCE.

THIBEAUT, C. (2003). Invitación a la filosofía. Madrid: Acento.

VERNANT, J. P. (1985). Mito y pensamiento en la antigua Grecia. Barcelona: Ariel. 